\title{
PSO-Backstepping Design for sharing Active and Reactive Power in grid connected DFIG based wind turbine.
}

\author{
${ }^{1}$ SALMI HASSAN $\ddagger,{ }^{1}$ BADRI ABDELMAJID, ${ }^{2}$ ZEGRARI MOURAD, ${ }^{1}$ SAHEL \\ AICHA, ${ }^{1}$ BAGUDAD ABDENACEUR \\ ${ }^{1}$ EEA\&TI Laboratory Faculty of Sciences and Techniques, Hassan II Casablanca \\ University, Mohammedia, MOROCCO \\ ${ }^{2}$ Structural Engineering, Intelligent Systems and Electrical Energy. ENSAM \\ Casablanca, MOROCCO
}

\begin{abstract}
An optimal backstepping controller is developed for doubly fed induction generator based wind turbine (DFIG). The objective is the control of active and reactive power exchanged between the generator and electrical grid in presence of uncertainty and reduce transient loads. The backstepping controller is coupled with an artificial bee colony aeroturbine algorithm in order to extract the maximum energy. Particle swarm optimization is used to select optimal value of backstepping's parameters. The simulation is carried out on 2.4 MW DFIG based wind turbine system. The optimized performance of the proposed control technique under uncertainty parameters and transient load is established by simulation results.
\end{abstract}

Key-Words: - Nonlinear Backstepping Controller; DFIG; PSO; reduction transient loads.

Received: May16, 2020. Revised: February 21, 2021. Accepted: March 17, 2021. Published: March 30, 2021.

\section{Introduction}

According to wind Europe [1], the total installed power capacity of wind industry has increased from $6 \%$ in 2015 to $18 \%$ in 2017 . The rapidly growing of wind turbine can be justified by little negative impact on environment. The kinetic energy of wind is harnessed by wind turbines and converted into mechanical energy and finally into electrical energy.

Recently, the optimal generator used for wind system is DFIG [2]. This generator is controlled to fulfill the strict requirement of electrical grid [9], to adequately maintain constant power and frequency, no matter the speed of the wind [3]. However, grid connected DFIG still has significant challenges to resolve, such as grid stability, MPPT and power quality [4]. Hence, integration of new developed control algorithms and high-efficient systems is regarded as a promising way to overcome that challenge.

Control strategy is a key factor for DFIG based wind turbine efficiency enhancement [5]. For several years, great effort has been devoted to the study of turbine control design [6] [7]. A substantial review of this effort is given on [4].

For several years great efforts has been devoted to test the quality control of the power for variable wind turbine system: reference [10] has developed PI controller to control the power of the wind turbine system; the second order sliding has been used to regulate the wind turbine system in accordance with references provided by Maximum Power Point Tracking algorithm in [11]; in reference [12] a controller based on direct-current vector has been used in DFIG to extract the maximum energy and control the reactive power. The adaptive feedback linearization controller has been developed in [13]. A nonlinear predictive controller has been proposed to extract power and transient load reduction by using predictions of the output power to optimize the control of sequence in [5].

In the literature, several theories have been proposed to explain the effectiveness of backstepping control; in [14], a backstepping controller is developed for standalone DFIG to control the stator output voltage and fulfilling the demand energy variations and impact of wind velocity. In [15] the mechanical and electrical parts of the system are controller by rotor currents. In [16] the author's attention are not focused in regulating the mechanical part, they just apply the control strategies to the generator side converter by combining the feedback form of backstepping with two takagi-suggen fuzzy system. In [17], authors compares PI controller and backstepping approach for controlling independently the extracted active and reactive 
power from the stator of DFIG to electrical grid. In [18], electrical and mechanical parts are controlling by using stator currents as references.

For our knowledge, any paper has taken into consideration the impact of rapid variation of wind and DFIG's parameter uncertainty on the performance of controller.

The objective of this work is the control of power extracted from the DFIG and injected to the grid taking into consideration the DFIG's parameters variations and wind speed turbulence which increases control efforts. Generally, the selection of backstepping's parameters is arbitrarily, in this work, we determine the best parameters of the backstepping controller by using particle swarm optimization (PSO).

In addition, artificial bee colony ( $\mathrm{ABC}$ ) algorithm proposed in [19] is used to maximize the extracted power by adjusting the rotor speed, according to wind speed, without knowledge of system parameters.

\section{Wind turbine system modeling:}

In this work, the considered system is a large variable speed wind turbine. Its architecture is shown in figure 1 [5]. The most important parts of the system are composed of two components. The mechanical part is composed of a rotor entrained by kinetic energy of wind and a gearbox, which makes the high-speed shaft to the right. The electrical component contain a (DFIG) and converter.

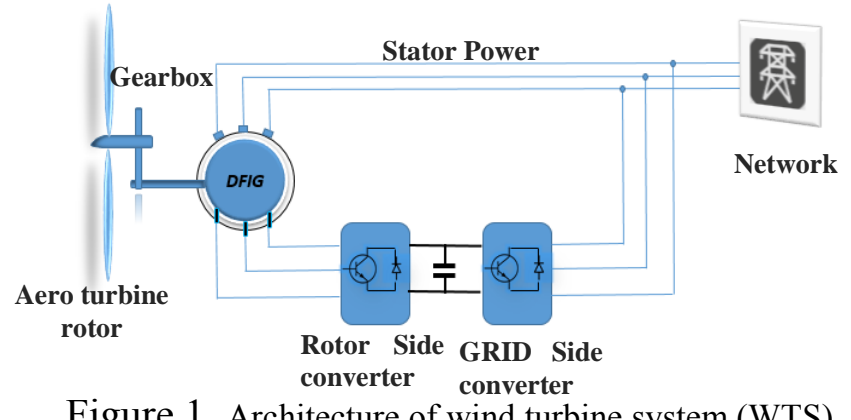

Figure 1. Architecture of wind turbine system (WTS)

\subsection{Mechanical part}

The mechanical power received by WTS is defined as:

$$
P_{t}=\frac{1}{2} \pi \rho R^{2} V^{3} C_{p}(\beta, \lambda)
$$

With:

$$
\begin{array}{ll}
\rho & : \text { the air density }\left[\mathrm{Kg} / \mathrm{m}^{3}\right] \\
R & : \text { the blade length }[\mathrm{m}] \\
V & : \text { The speed of wind }[\mathrm{m} / \mathrm{s}] . \\
C_{p} & : \text { the power coefficient } \\
\beta & : \text { pitch angle. } \\
\lambda & : \text { tip speed ratio }
\end{array}
$$

The relation between $C_{p}, \lambda$ and $\beta$ is defined by [27]:

$C_{p}(\lambda, \beta)=c_{1}\left(c_{2} \frac{1}{A}-c_{3} \cdot \beta-c_{4}\right) e^{-c_{5} \frac{1}{A}+c_{6} \lambda(2)}$

With: $\quad c_{1}=0.5872, \quad c_{2}=116, \quad c_{3}=0.4, \quad c_{4}=5, c_{5}=21$, $c_{6}=0.0085$.

$$
\frac{1}{A}=\frac{1}{\beta+0.08}-\frac{0.035}{1+\beta^{3}}
$$

The formula of the tip ratio is provided by:

$$
\lambda=\frac{\Omega_{t} R}{V}(3)
$$

Where $\Omega_{t}$ is the rotor speed. Furthermore, the mechanical torque on the rotor is calculated by:

$$
T_{m}=\frac{P_{t}}{\Omega_{t}}=\frac{0.5 \pi \rho R^{3} V^{2} C_{p}(\beta, \lambda)}{\lambda}
$$

The mechanical angular speed and torque on the axis of generator DFIG is given by:

$$
\left\{\begin{array}{c}
\Omega_{g}=\mathrm{M} \Omega_{t} \\
T_{g}=\frac{T_{m}}{M}
\end{array}\right\}
$$

$\mathrm{M}$ is the multiplication ratio. 
In order to calculate the mechanical angular $\Omega_{g}$, we apply the fundamental equation of dynamic:

$$
\left\{\begin{array}{l}
\mathrm{J} \dot{\Omega}_{g}=T_{m}-\mathrm{M} T_{e}-\mathrm{f} . \Omega_{g} \\
\mathrm{~J}=J_{r}+M^{2} J_{g}
\end{array}\right.
$$

Where $\mathrm{J}$ is the total rotational inertia, $\mathrm{M}$ is gear ratio of turbine, $\mathrm{Te}$ is electromagnetic torque. The damping coefficient $\mathrm{f}$ is overlooked because it is lowest than rotational inertia [10].

Therefore, the mathematic equation which model our system is:

$$
\mathrm{J} \dot{\Omega}_{g}=T_{m}-\mathrm{M} T_{e} \rightarrow \dot{\Omega_{g}}=\frac{0.5 \pi \rho R^{3} V^{2} C_{P} \max }{J M^{3} \lambda_{o p t}{ }^{3}} \Omega_{g}{ }^{2}-\frac{M T_{e}}{J}
$$

\subsection{Electrical model}

The voltages and magnetic equations of the DFIG in dq reference are given by [3]:

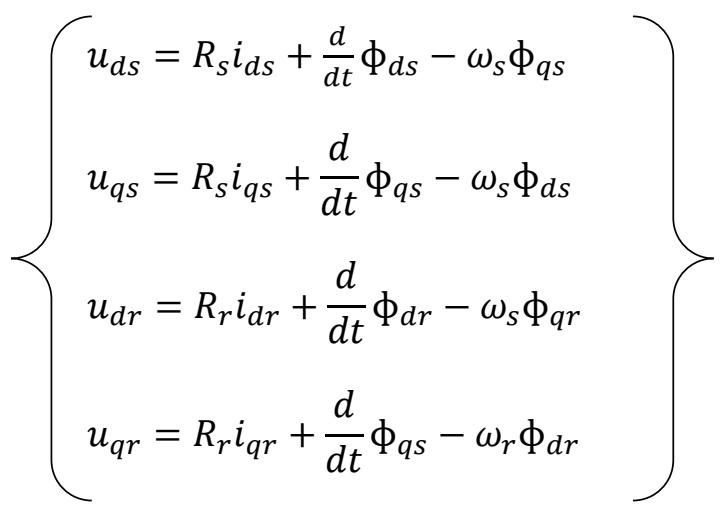

With: $\omega_{r}=\omega_{s}-\mathrm{P} \Omega \mathrm{g}$

$$
\begin{aligned}
& \phi_{d s}=L_{s} i_{d s}+\mathrm{M} i_{d r} \\
& \phi_{q s}=L_{s} i_{q s}+\mathrm{M} i_{q r} \\
& \phi_{d r}=L_{r} i_{d r}+\mathrm{M} i_{d s} \\
& \phi_{q r}=L_{r} i_{q r}+\mathrm{M} i_{q s}
\end{aligned}
$$

And :

$L_{s}=l_{s}-M_{s}$

$L_{r}=l_{r}-M_{r}$

$L_{s}, L_{r}:$ rotor and stator cyclic inductances

$l_{s}, l_{r}:$ stator and rotor inductances.

$M_{s}, M_{r}:$ Mutual inductances;

$\mathrm{M}=\operatorname{Max}\left(M_{S}, M_{r}\right)$

The electromagnetic torque and power equations at the stator are expressed by [4]:

$$
\begin{aligned}
& T_{e}=\frac{3}{2} * \mathrm{p}^{*}\left(\phi_{q s} i_{d s}-\phi_{d s} i_{q s}\right) \\
& P_{\text {stator }}=\frac{3}{2}\left(u_{d s} i_{d s}+u_{q s} i_{q s}\right) \\
& Q_{\text {stator }}=\frac{3}{2}\left(u_{q s} i_{d s}-u_{d s} i_{q s}\right)
\end{aligned}
$$

\section{Power capture optimization:}

The evolution of the power extracted from a wind turbine according to the speed of the wind is presented in the figure 2 .

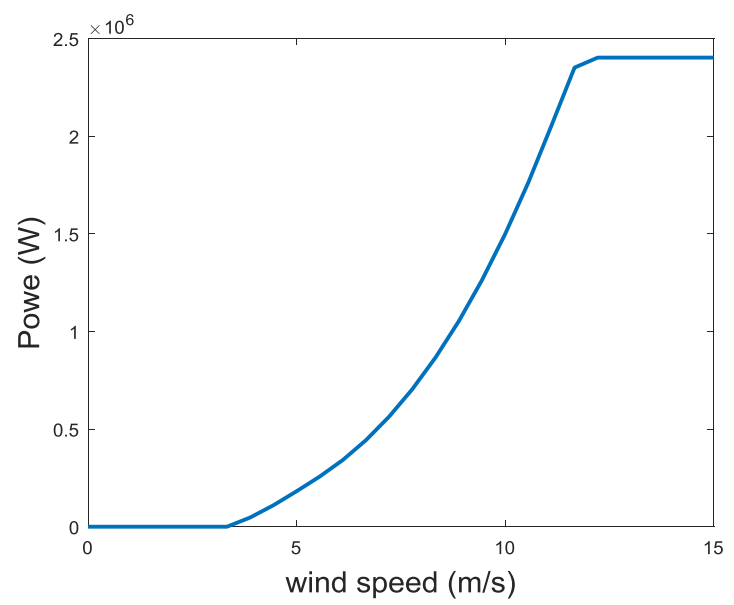

Figure 2: wind power depending on the wind

As shown in figure 2, the system is designed to operate with a specific interval of wind speed. The limit of the range are known as the lower speed $V_{\text {cut }}$ and top speed $V_{\text {cout }}$ (typically around 9 to 15 $\mathrm{m} / \mathrm{s}$ [26]). In this interval, the controller must optimize the power extracted.

This extracted power is usually dependent on the value of $C_{p}$, which must be set at its optimum 
value $C_{p_{\text {opt }}}$. Therefore, $\beta$ and $\lambda$ must be optimal. $\lambda=\lambda_{\text {opt }} ; \beta=\beta_{\text {opt }}$.

In order to fix an optimal tip speed ratio, the rotational speed $\omega_{t}$ of the rotor must follow the optimal value $\omega_{\text {opt }}$ value:

$\omega_{o p t}=\frac{\lambda_{o p t}}{R} v$

Most of the previous studies have not consider wind speed turbulence which increases control efforts. In this paper, a compromise between power capture efficiently and load reduction is obtained by a suitable selection of the controller bandwith.

\section{Power control approach}

The principal objective of the proposed control is capturing the maximum power of the incident energy of the system by adjusting the rotational speed, and control the active and reactive power of the system with large inertia exchanged between (DFIG) and the grid in presence of parameter's uncertainty such as resistance, inductance and tip speed ratio variations.

\subsection{Maximum power point tracking (MPPT):}

The MPPT algorithm is employed on region between Vcut and Vcout to capture maximum power point (MPP) for all wind speeds.

In the literature, several MPPT algorithms have been discussed so far [2]. These methods are effective for wind turbine with low inertia. But, for high inertia, it takes more time and don't offer effective results.

According to equation 1, whatever the wind speed, the maximum power extracted is obtained when power coefficient is optimum [3] (figure 3).

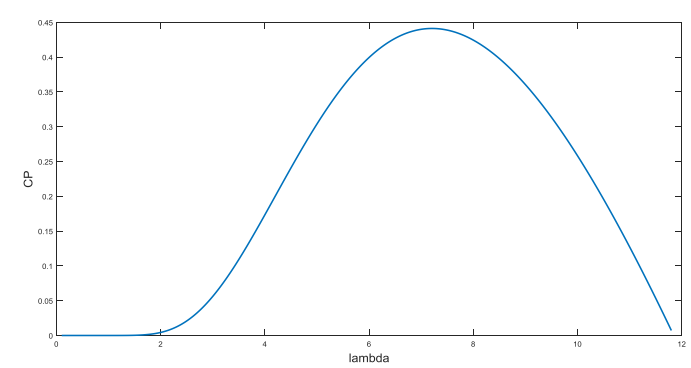

Figure 3: Power coefficient for a specific wind turbine
In this paper, a novel solution to MPPT based on $\mathrm{ABC}$ algorithm [17] under variable wind speeds. Only one other study [3], to our knowledge, has come up with ABC based MPPT but without taking into account wind speed turbulence.

The $\mathrm{ABC}$ algorithm includes three main groups: employed, onlooker and scouts. Each group has a well-defined role [9] .

The process of the $\mathrm{ABC}$ algorithm is established in [9].

In this paper, with Artificial Bee colony (ABC), we determine the reference value of rotor speed that should be applied to extract the maximum power.

To concretize the control of Artificial Bee Colony based MPPT, each solution is defined as the rotational speed and the output power of system as the nectar amount.

The initial rotor speed will become:

$\Omega_{i}=\Omega_{\text {min }}+\operatorname{rand}(0,1) *\left(\Omega_{\max }-\Omega_{\text {min }}\right)$

New solution: new $-\Omega_{i}=\Omega_{i}+$ कi $\left(\Omega_{i}-\Omega_{k}\right)$

The fitness of each candidate is assessed by its generated output active power:

$\mathrm{Pi}=\frac{P_{m i}}{\sum_{i}^{s n} P i}$

The detail of the $\mathrm{ABC}$ algorithm used in this paper to determine the optimal speed is below:

- Insert the maximum cycle and number of initial candidate.

- Generate randomly the rotor speed (employed bees).

- Calculate the power of each rotor speed.

- Repeat:

- Modify the rotor speed according to (18).

- Evaluate the power of the new solution.

- Apply the greedy selection for each rotor speed.

- Evaluate the probability according to (20).

- fix the onlooker bees basing on the probability and edit each candidate (18)

- Apply the greedy selection for each onlooker bees.

- Fix the scouts bees and replace it by (18).

- Memorize the optimal solution

- Increment the cycle until Maximum cycle MCN.

\subsection{Electrical part:}


According to (8), the nonlinearity of the generator's model is due to the coupling between the rotor speed and the currents. We annul the direct axis current $i_{d}$ in order to align flux $\phi_{s}$ in d-axis [10]. We obtain:

$\phi_{s d}=\phi_{s} ; \phi_{s q}=0$

Therefore from (10), we obtain:

$i_{d s}=-\frac{M}{L_{S}} i_{d r}+\frac{\phi_{s d}}{L_{S}}$

$i_{q s}=-\frac{M}{L_{S}} i_{q r}$

In addition, we notice that stator is connected to a stable grid, stator resistive is neglected.

Therefore the stator equation are reduced to:

$$
\begin{gathered}
u_{d s}=R_{s} i_{d s} \\
u_{q s}=R_{s} i_{q s}-\omega_{s} \phi_{d s}
\end{gathered}
$$

Therefore, the stator powers can be expressed [5]:

$$
\begin{aligned}
& P_{S}=\frac{-3 M}{2 L_{S}} V_{S q} I_{r q} \\
& Q_{S}=\frac{-3 M}{2 L_{S}} V_{S q} I_{r d}+\frac{3}{2 L_{S} \omega_{S}} V_{S q}{ }^{2}
\end{aligned}
$$

The double fed induction generator is controlled by rotor voltage. Therefore we should set the relation between currents and voltages of rotor circuit:

$$
V_{r d}=R_{r} I_{r d}+\sigma L_{r} I_{r d}^{\cdot}-\omega_{r} \sigma L_{r} I_{r q}
$$

$V_{r q}=R_{r} I_{r q}+\sigma L_{r} I_{r q}^{\cdot}+\omega_{r} \sigma L_{r} I_{r d}+\omega_{r} \frac{L_{m} V_{s q}}{L_{s} \omega_{s}}$

Where $\sigma=\frac{L_{r} L_{S}-M^{2}}{L_{r} L_{S}}$.

The faults in DFIG are dominated by stator and rotor winding insulation faults, short circuits in stator circuit, variable resistance faults, cracked rotor end rings ....

Equations. (7) and (27) end up:

$$
\begin{aligned}
& \dot{\Omega_{g}}=\frac{0.5 \pi \rho R^{5} C_{P}{ }^{\max }}{J G^{3} \lambda_{o p t}{ }^{3}} \Omega_{g}{ }^{2}-\frac{M T_{e}}{J}+\frac{0.5 \pi \rho R^{5}}{J G^{3}}\left(\frac{\Delta C_{P}}{\lambda_{o p t}{ }^{3}}+\right. \\
& \left.3 \frac{C_{P} \Delta \lambda}{J \lambda_{\text {opt }}{ }^{4}}\right) \Omega_{g}{ }^{2}{ }^{2}(28)
\end{aligned}
$$

$$
\begin{aligned}
& I_{r d}^{\cdot}=-\frac{\left(L_{r}+\Delta L_{r}\right)\left(L_{S}+\Delta L_{S}\right)}{\left(L_{r}+\Delta L_{r}\right)\left(L_{S}+\Delta L_{S}\right)-(M+\Delta M)^{2}} \frac{\left(R_{r}+\Delta R_{r}\right)}{\left(L_{r}+\Delta L_{r}\right)} \\
& * I_{r d}+\left(\omega_{r}-\right. \\
& \left.P \Omega_{g}\right) I_{r q}+\frac{\left(L_{r}+\Delta L_{r}\right)\left(L_{s}+\Delta L_{s}\right)}{\left(L_{r}+\Delta L_{r}\right)\left(L_{s}+\Delta L_{s}\right)-(M+\Delta M)^{2}} \frac{1}{\left(L_{r}+\Delta L_{r}\right)} * V_{r d} \\
& \dot{I_{r q}}=-\frac{\left(L_{r}+\Delta L_{r}\right)\left(L_{S}+\Delta L_{S}\right)}{\left(L_{r}+\Delta L_{r}\right)\left(L_{S}+\Delta L_{S}\right)-(M+\Delta M)^{2}} \frac{\left(R_{r}+\Delta R_{r}\right)}{\left(L_{r}+\Delta L_{r}\right)} * I_{r q}+ \\
& \left(\omega_{s}-P \Omega_{g}\right) I_{r d^{-}}\left(\omega_{s}-P \Omega_{g}\right) \quad * \frac{L_{m}}{\left(L_{r}+\Delta L_{r}\right) \omega_{s\left(L_{s}+\Delta L_{s}\right)}} \\
& * V_{s q}+\frac{\left(L_{r}+\Delta L_{r}\right)\left(L_{S}+\Delta L_{S}\right)}{\left(L_{r}+\Delta L_{r}\right)\left(L_{S}+\Delta L_{S}\right)-(M+\Delta M)^{2}} \frac{1}{\left(L_{r}+\Delta L_{r}\right)} * V_{r q}
\end{aligned}
$$

Where $\Delta R_{r}, \Delta L_{r}, \Delta L_{s}, \Delta M, \Delta \lambda$ and $\Delta C_{P}$ are the rotor resistance and inductance variation, the stator resistance and inductance variation, and discrepancy in the calculation. of $\lambda_{O P T}$ and $C_{P}$, respectively.

By using partial derivative, we obtain:

$$
\begin{aligned}
& \dot{\Omega_{g}}=\frac{0.5 \pi \rho R^{5} C_{P}{ }^{\max }}{J G^{3} \lambda_{o p t}{ }^{3}} \Omega_{g}{ }^{2}-\frac{M T_{e}}{J}+\Delta 1 \\
& I_{r d}^{\cdot}=-\frac{R_{r}}{L_{r} \sigma} I_{r d}+\omega_{r} I_{r q}+\frac{1}{\sigma L_{r}} V_{r d}+\Delta 2 \\
& \dot{I_{r q}}=-\frac{R_{r}}{L_{r} \sigma} I_{r q}-\omega_{r} I_{r d}-\omega_{r} \frac{M}{\omega_{s} \sigma L_{r} L_{s}} V_{s q}+\frac{1}{L_{r} \sigma} V_{r q}+\Delta 3
\end{aligned}
$$

With:

$$
\begin{aligned}
& \boldsymbol{\Delta} 1=\frac{0.5 \pi \rho R^{5}}{J G^{3}}\left(\frac{\Delta C_{P}}{\lambda_{o p t}{ }^{3}}+3 \frac{C_{P} \Delta \lambda}{J \lambda_{o p t}}\right) \Omega_{g}{ }^{2} \\
& \boldsymbol{\Delta} 2=\left(\frac{\Delta L_{r} * R_{r}}{\sigma^{2} * L_{r}{ }^{2}}+\frac{\Delta R_{r}}{\sigma L_{r}}+\frac{\Delta L_{s} * R_{r}}{\sigma L_{r} L_{s}}+\frac{\Delta L_{s} * R_{r}}{\sigma^{2} L_{r} L_{s}}+\frac{2 * \Delta M * M * R_{r}}{\sigma^{2} L_{r} L_{s}}\right) I_{r d}+ \\
& \left(\frac{\Delta L_{r}}{\sigma^{2} * L_{r}{ }^{2}}+\frac{\Delta L_{s}}{\sigma L_{r} L_{s}}+\frac{\Delta L_{s}}{\sigma^{2} L_{r} L_{s}}+\frac{2 * \Delta M * M}{\sigma^{2} L_{r} L_{s}}\right) V_{r d} \\
& \boldsymbol{\Delta} 3= \\
& \left(\frac{\Delta L_{r} * R_{r}}{\sigma^{2} * L_{r}^{2}}+\frac{\Delta R_{r}}{\sigma L_{r}}+\frac{\Delta L_{s} * R_{r}}{\sigma L_{r} L_{S}}+\frac{\Delta L_{s} * R_{r}}{\sigma^{2} L_{r} L_{s}}+\frac{2 * \Delta M * M * R_{r}}{\sigma^{2} L_{r} L_{s}}\right) I_{r q}+\left(\frac{\Delta L_{r}}{\sigma^{2} * L_{r}^{2}}+\right. \\
& \left.\frac{\Delta L_{s}}{\sigma L_{r} L_{s}}+\frac{\Delta L_{s}}{\sigma^{2} L_{r} L_{s}}+\frac{2 * \Delta M * M}{\sigma^{2} L_{r} L_{s}}\right) V_{r q}+
\end{aligned}
$$

$$
\left(\frac{\Delta L_{s} * \omega_{r} M}{\omega_{s} * \sigma^{2} * L_{r} * L_{s}{ }^{2}}+\frac{\Delta L_{r} * \omega_{r} * M}{\omega_{s} * \sigma^{2} * L_{s} * L_{r}{ }^{2}}\right) V_{s q}
$$

- Application of Backstepping controller in Double Fed Induction Generator:

The nonlinear Backstepping approach is a method that can efficiently linearize a complex nonlinear system in the presence of parameter's uncertainties. The essence of this method consists the decomposing of the system into many subsystems, 
design the Lyapunov function and virtual function for each subsystem. Therefore, it uses an error variable that can be stabilized by choosing the optimized control based on the study of lyapunov stability.

Taking into account that the variation of parameters $\Delta R_{s}, \Delta L_{s}, \Delta L_{r}, \Delta M, \Delta C_{P}$ and $\Delta \lambda$ are finite. Therefore, the function $\Delta 1, \Delta 2$ and $\Delta 3$ are bounded:

$$
\left|\Delta_{1}\right| \leq \rho_{1} ;\left|\Delta_{2}\right| \leq \rho_{2} ;\left|\Delta_{3}\right| \leq \rho_{3}
$$

\section{Step1:}

In order to force the generator angular speed at the desired reference $\Omega_{g}$ ref and stabilize the error dynamic, we define the positive lyapunov function:

$V_{\Omega}=0.5 e_{\Omega}^{2}$

The error tracking is defined as:

$$
e_{\Omega}=\Omega_{g}-\Omega_{g} \text { ref }
$$

The derivative of this function is:

$\dot{V_{\Omega}}=e_{\Omega} * \dot{e_{\Omega}}=e_{\Omega}\left(\frac{0.5 \pi \rho R^{5} C_{P}{ }^{\max }}{J G^{3} \lambda_{\text {opt }}{ }^{3}} \Omega_{g}{ }^{2}-\frac{M T_{e}}{J}+\Delta 1-\right.$ $\left.\Omega_{g} \dot{r} e f\right)$

In order to guarantee $\Omega_{g}$ tracks $\Omega_{g}{ }^{\text {ref }}$, the derivative must be always negative. Therefore, $T_{e}^{r e f}$ must be chosen as:

$T_{e}^{r e f}=\frac{0.5 \pi \rho R^{5} C_{P}{ }^{\text {max }}}{G^{3} \lambda_{\text {opt }}{ }^{3}} \Omega_{g}{ }^{2}-\frac{M T_{e}}{J}+\Delta 1-\mathrm{J} \Omega_{g}{ }^{\dot{r} e f}+$

$J K_{1} e_{\Omega}+\mathrm{J} y_{1} \operatorname{sign}\left(e_{\Omega}\right)$

With $y_{1} \geq \rho_{1}$

$K_{1}$ is the feedback gain.

This choice makes $\dot{V}_{\Omega}$ negative.

After calculation of electromagnetic torque, the quadrature rotor current reference are:

$$
\begin{aligned}
& I_{r q}{ }^{r e f}=-\frac{L_{s}}{P M \phi_{s}} \\
& \left.J K_{1} e_{\Omega}+\mathrm{J} y_{1} \operatorname{sign}\left(e_{\Omega}\right)\right) \quad(34)
\end{aligned}
$$

To maintain a unit power factor, the reactive power should be fixed at zero: $Q_{s}=0$
From (19), we obtain: $I_{r d}{ }^{r e f}=\frac{V_{s q}}{M \omega_{s}}$

\section{Step2:}

The calculation of rotor voltage is primary to force the currents follow $I_{r q}{ }^{r e f}$ and $I_{r d}{ }^{r e f}$.

The lyapunov function is

$V=0.5 e_{\Omega}^{2}+0.5 e_{r d}^{2}+0.5 e_{r q}^{2}$

Where

$e_{r d}=I_{r d}-I_{r d}^{r e f}$

$e_{r q}=I_{r q}-I_{r q}^{r e f}$

The derivative of lyapunov function is:

$\dot{V}=e_{\Omega} * \dot{e_{\Omega}}+e_{r d} * \dot{e_{r d}}+e_{r q} * \dot{e_{r q}}=-K_{1} e_{\Omega}^{2}-\left(y_{1}-\right.$

$\left.\rho_{1}\right)\left\|e_{\Omega}\right\|+e_{r d} *\left(-\frac{R_{r} I_{r d}}{L_{r} \sigma}+\omega_{r} I_{r q}+\frac{1}{\sigma L_{r}} v_{r d}+\Delta_{2}-\right.$

$\left.I_{r d}{ }^{d}\right)+e_{r q} *\left(-\frac{R_{r} I_{r q}}{L_{r} \sigma}-\omega_{r} I_{r d}-\omega_{r} \frac{M}{\omega_{s} \sigma L_{r} L_{s}} v_{s q}+\right.$

$\left.\frac{1}{\sigma L_{r}} v_{r q}+\Delta_{3}-I_{r q}{ }^{d}\right)$

By taking the following control $V_{r d}$ and $V_{r q}$ :

$$
\begin{array}{r}
V_{r d}=\sigma L_{r}\left[-K_{2} e_{r d}-y_{2} \operatorname{sign}\left(e_{r d}\right)+\frac{R_{r} I_{r d}}{L_{r} \sigma}\right. \\
\left.-\left(\omega_{s}-P \Omega_{g}\right) I_{r q}+I_{r d}^{r^{r e f}}\right]
\end{array}
$$

$V_{r q}=\sigma L_{r}\left[-K_{3} e_{r q}-y_{3} \operatorname{sign}\left(e_{r q}\right)+\frac{R_{r} I_{r q}}{L_{r} \sigma}+\right.$
$\left(\omega_{s}-P \Omega_{g}\right) I_{r d}+I_{r q} \cdot r e f$

With $K_{2}$ and $K_{3}$ are feedback gain. We obtain

$\dot{V} \leq-K_{1} \quad e_{\Omega}^{2}-\left(y_{1}-\rho_{1}\right) \quad\left\|e_{\Omega}\right\|-K_{2} e_{r d}{ }^{2}-K_{3} e_{r q}{ }^{2}-y_{2}\left\|e_{r d}\right\|-$ $y_{3}\left\|e_{r q}\right\|+\left\|e_{r d}\right\| \Delta_{2}+\left\|e_{r q}\right\| \Delta_{3}$

Which implies that our system is asymptotically stable.

The choice of $K_{1}, K_{2}$ and $K_{3}$ is heuristic, for these we propose the PSO method these parameters.

\section{Result and Simulation:}

The simulation is realized in MATLAB/Simulink with the parameters of a $2.4 \mathrm{MW}$ machine. In order 
to verify asymptotic stability of our controller and show its performance, we implemented the system that includes wind turbine, (DFIG) and converter.

The simulation has been realized for a wind speed from $9 \mathrm{~m} / \mathrm{s}$ to $15 \mathrm{~m} / \mathrm{s}$ as shown in Figure. 5. Table 1 shows the parameters of the DFIG based wind turbine.

The author's attention was focused not only on transient state but also on steady state analysis with the most representative magnitude of the DFIG in order to demonstrate the effectiveness and the merit of our controller.

From figure 4, it can be seen that the input of the generator (Electromagnetic torque Tem) in function of the rotational speed is negative, therefore the machine is operated as generator.

The maximum mechanical power is $2.4 \mathrm{Mw}$ and we have also calculated active power at the stator and rotor with maximum power of the stator is $2 \mathrm{MW}$ and for the rotor is $0.4 \mathrm{MW}$;

The stator voltage is directly connected to the grid therefore it always constant.

For the rotor voltage depends on the speed with $1450(\mathrm{rpm})$ is the synchronous speed.
Figure 4: steady state analysis

Once we have the steady state analysis, we can check it in our system controlled by backstepping controller.

In this paper, PSO is used to select efficient parameters of controller in order to converge rapidly to the optimal functioning.

PSO algorithm introduced by Kennedy and Eberhart in 1995 [13], is inspired by social behavior of bird flocking or fish schooling, characterized as a simple structure, easy to implement, computationally efficient and quick convergence than other genetic methods such as genetic algorithms "GAs"[4].

PSO algorithms use particles which represent potential solutions of the problem. It is first initialized with a group of random particles. In each iteration, every solution is modified at a certain velocity by following two best solutions (fitness). The personal best $P_{\text {best }}$ which is the best value achieved by each solution and the global best $g_{\text {best }}$ is the best value of all particles.

The position $X_{i}$ and the velocity $Y_{i}$ of each particle of the population are defined as the following two equations:

$Y_{i+1}=\omega \cdot Y_{i}+c_{1} \cdot r_{1}\left(P_{b e s t}-X_{i}\right)+c_{2} \cdot r_{2}\left(g_{b e s t}-X_{i}\right)$

$X_{i+1}=Y_{i+1}+X_{i}$
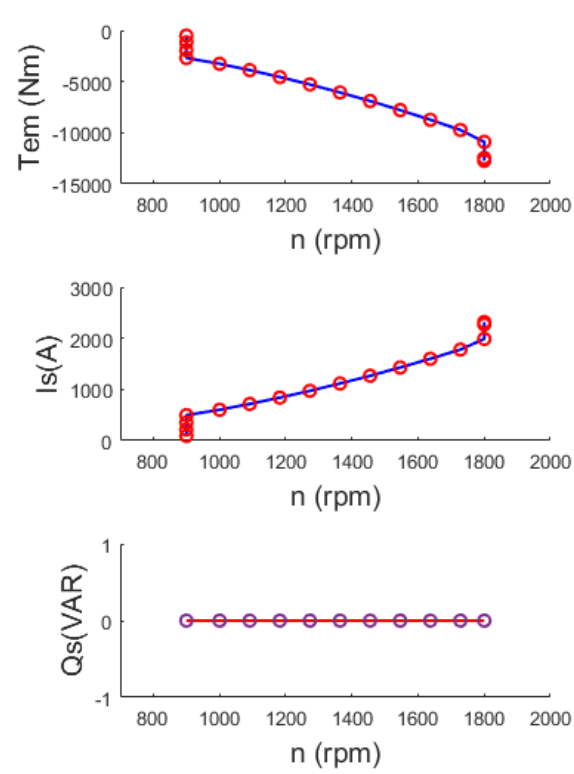
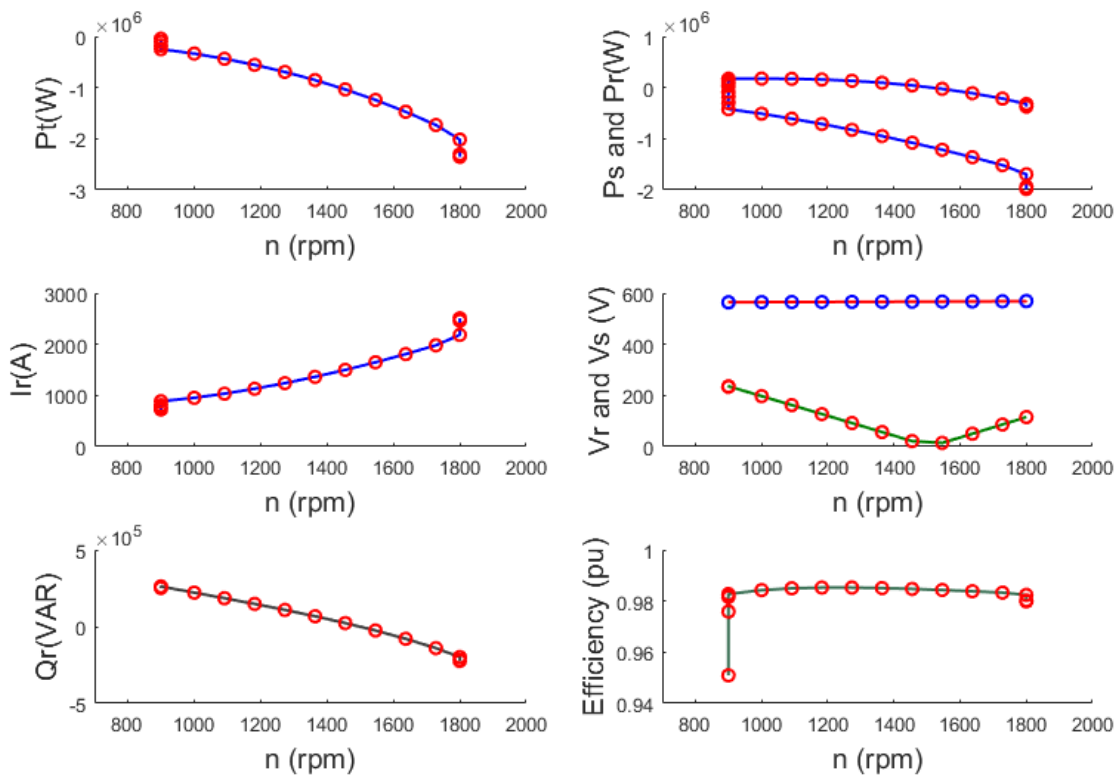


\begin{tabular}{|c|c|c|c|}
\hline Mutual inductance & $0.0025 \mathrm{H}$ & $\begin{array}{c}\text { Coefficient of } \\
\text { the viscous } \\
\text { damping (f) }\end{array}$ & $\begin{array}{c}0.01 \mathrm{~N} \mathrm{~m} / \mathrm{rad} \\
\mathrm{s}\end{array}$ \\
\hline
\end{tabular}

Where $Y_{i}$ the velocity of the particle is, $X_{i}$ is the solution. $r_{1}$ and $r_{2}$ are random numbers. $c_{1}$ and $c_{2}$ are usually between 1.5 and 2.5 and finally $\omega$ is the inertia factor.

The PSO algorithm used in this paper consists of the following steps:

1. population of particles is generated with random position and velocities (parameters $k_{1}, k_{2}, k_{3}$ ) (population size 50 ).

2. The fitness of each candidate solution is generated (objective function)

3. select the $P_{\text {best }}$ and $g_{\text {best }}$.

4. First iteration

5. Velocity updating : the velocities of all particles are edited according to equation of $Y_{i+1}$

6. Position updating: the position of all particles are updated according to the equation () Xi

7. Evaluate the fitness of each new individual

8. Compare the new individual with $P_{\text {best }}$ and $g_{\text {best }}$.

9. Go back to step 4 until final iteration (maximum of iterations is 15)

10. Finally, the optimal position will be the solution of optimization problem.

In order to converge rapidly to the best solution, we minimize a certain criterion such as the mean square error can be calculated by the following equation:

Mean square error $=\frac{1}{N T} \sum_{i=1}^{N} e_{\Omega}^{2}+e_{r d}^{2}+e_{r q}^{2}$

$\mathrm{N}$ is the total number of samples,

T: the sampling time

\begin{tabular}{|c|c|c|c|}
\hline Parameters & $\begin{array}{c}\text { Numerical } \\
\text { value }\end{array}$ & Parameters & $\begin{array}{c}\text { Numerical } \\
\text { value }\end{array}$ \\
\hline $\mathrm{Lr}$ & $0.0026 \mathrm{H}$ & $\begin{array}{c}\text { Multiplication } \\
\text { ratio }\end{array}$ & 100 \\
\hline $\mathrm{Rr}$ & $0.0029 \Omega$ & $\boldsymbol{\rho}$ & $1.225 \mathrm{Kg} / \mathrm{m}^{3}$ \\
\hline $\mathrm{Ls}$ & $0.0026 \mathrm{H}$ & $\begin{array}{c}\text { Blade length } \\
(\mathrm{R})\end{array}$ & 42 \\
\hline $\mathrm{Rs}$ & $0.0021 \Omega$ & $\begin{array}{c}\text { Number of } \\
\text { pairs poles }(\mathrm{p})\end{array}$ & 2 \\
\hline
\end{tabular}

\section{Table 1: The parameters of the system}

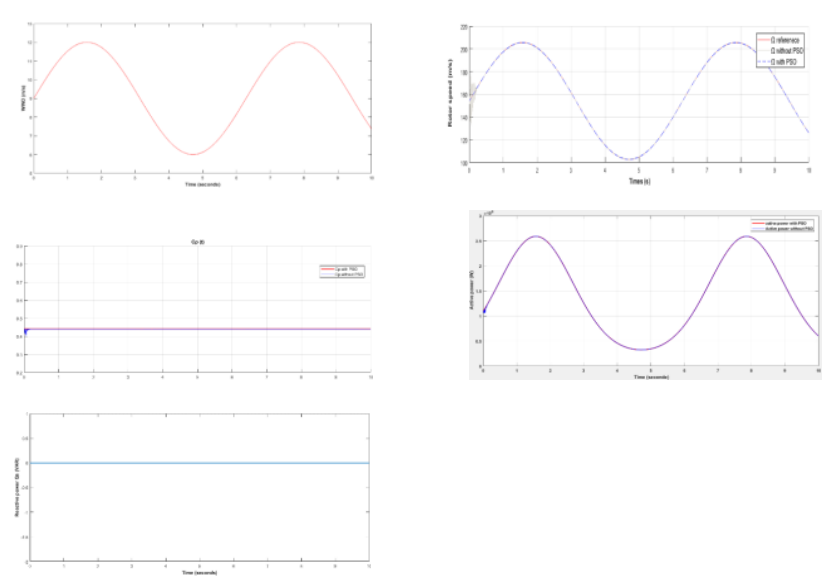

Figure 5: simulation without parameters variation
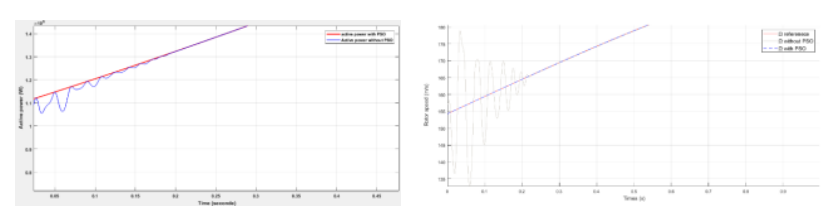

Figure 6: simulation without parameters variation (ZOOM)

The determination of speed reference, which track the speed of the wind, is given by Artificial Bee colony algorithm and then used by backstepping controller to regulate the speed of DFIG. The schematic of our control strategy is given in figure 7.

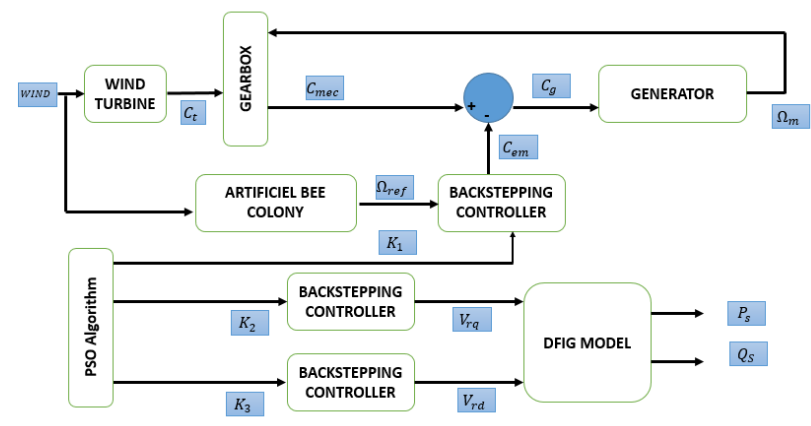

Figure 7. Schematic of control strategy 
To verify the robustness of this proposed controller, PSO-Backstepping is compared with arbitrary backstepping controller which is implemented on recent works [21-25].

The simulation results obtained without parameter variation in figure 5 show that angular speed and active power converges quickly to their references values with optimal reactive power $(\mathrm{Q}=0 \mathrm{VAR})$.

In figure 6, we observe that our proposed controller converges quickly towards the optimal trajectory and this is due to the good selection of the parameters by the PSO algorithm whatever the variation of the wind $\left(K_{1}, K_{2}\right.$ and $\left.K_{3}\right)$.

In order to evaluate the robustness of the our controller with presence of uncertainty, we have considered $\quad \Delta L_{r}=\Delta L_{s}=\Delta M=5 \%, \quad \Delta R_{r}=90 \%$, $\Delta C_{P}=6 \%$ and $\Delta \lambda=5 \%$.

It can be seen in figure 8 that the robustness of our proposed controller does not affected by the variation of DFIG's parameters. Also the particle swarm optimization selects the best value of parameters for tracking rapidly the best trajectory.
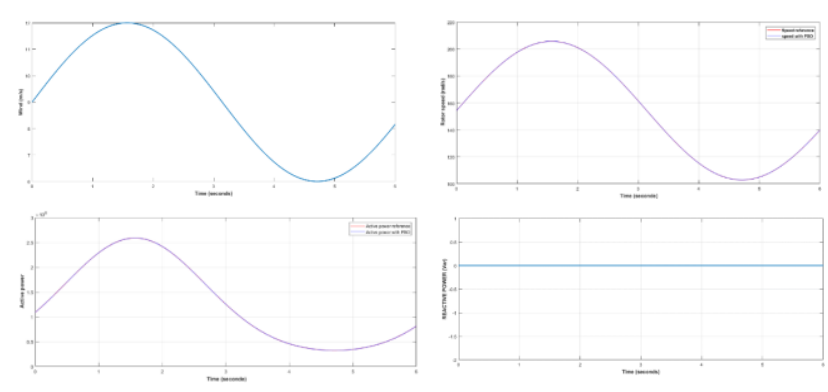

Figure 8: simulation with parameters variation

\section{Conclusion}

From the outcome of our investigation, it is possible to conclude that the backstepping controller with particle swarm optimization can solve the challenge of controlling the power extracted in presence of DFIG's parameters uncertainties which is due to technical problem in the generator. The $\mathrm{ABC}$ algorithm is applied to select the reference of rotational speed of wind turbine whatever the wind in order to extract the maximum power in real time. The robustness of the controller is demonstrated by simulation results.

\section{Acknowledgements}

This paper is part of project SISA1 between research center SISA and Hassan II University.

\section{References:}

[1] Wind in power 2017, Wind Europe.

[2] calculation steady-state operating conditions for DFIG-based wind turbine, Meng $\mathrm{Wu}$, Le Xie, IEEE Transactions on sustainable Energy ( Volume: 9 , Issue: 1, Jan. 2018 )

[3] Principles of doubly fed induction generators (DFIG), Renewable energy, 2011.

[4] "Maximum power point tracking and output power control on pressure coupling wind conversion system", Hoang thinh do, Tri Dung Dang, Hoai $\mathrm{Vu}$ Anh Truong, Kyoung Kwan Ahn, IEEE Transactions on Industrial Electronics, Volume 65 issue 2, Feb 2018.

[5] A. Bektache, B. Boukhezzar,"Nonlinear predictive control of a DFIG-based wind turbine for power capture optimization" International journal of electrical power \&Energy systems",volume 101,October2018, pages $92-102$

[6] Jackson G.Njiri, Nejra Beganovic, Manh H.Do, DirkSöffker, "Consideration of lifetime and fatigue load in wind turbine", Volume 131, February 2019, pages 818-828

[7] Linyun Xiong, Penghan Li, Fei Wu, Meiling Ma, Muhammad Wassem Khan, Jir Wang, "A coordinated high-order sliding mode control of DFIG wind turbine for power optimization and grid synchtonization", Volume 105, February 2019, Pages 679-689.

[8] Hossein Torkaman, Ali Keyhani,"A review of design consideration for Doubly Fed Induction Generator based wind energy system", Electric Power Systems Research. Volume 160, July 2018, Pages $128-141$.

[9] H.T.Jadhav, Ranjit Roy, "A comprehensive review on the grid integration of doubly fed induction generator", Electrical power and energy systems, Elsevier 2013.

[10] Belmokhtar, K., Doumbia, M.L., Agbossou, K. : Modélisation et commande d'un système éolien à base de machine asynchrone à double alimentation pour la fourniture de puissances au réseau électrique, International Conference on Electrical Engeneering (CIGE), pp. 54-62. Bechar (2010).

[11] B. Beltran, M. E. H. Benbouzid and T. AhmedAli, "Second-Order Sliding Mode Control of a Doubly Fed Induction Generator Driven Wind Turbine," in IEEE Transactions on Energy Conversion, vol. 27, no. 2, pp. 261-269, June 2012. 
[12] S. Li, T. A. Haskew, K. A. Williams and R. P. Swatloski, "Control of DFIG Wind Turbine With Direct-Current Vector Control Configuration," in IEEE Transactions on Sustainable Energy, vol. 3, no. 1, pp. 1-11, Jan. 2012.

[13] Mullane, A., Lightbody, G., Yacamini, R.: Adaptive control of variable speed wind turbines. Rev. Energ. Ren. Power Eng. 101110 (2001).

[14] N. Bouchiba, A. Barkia, S. Sallem, L. ChrifiAlaoui, S. Drid and M. Kammoun, "A real-time Backstepping control strategy for a doubly fed induction generator based wind energy conversion system," 2017 6th International Conference on Systems and Control (ICSC), Batna, 2017, pp. 549-554.

[15] Elmansouri, A., Elmhamdi, J., Boualouch, A.: Control by back stepping of the DFIG used in the wind turbine. Int. J.Emerg. Technol. Advanced Eng. 5, 472-478 (2015).

[16] Aounallah, Tarek; Essounbouli, Najib; Hamzaoui, Abdelaziz; Bouchafaa, Farid: 'Algorithm on fuzzy adaptive backstepping control of fractional order for doubly-fed induction generators', IET Renewable Power Generation, 2018, 12, (8), p. 962-967

[17] Mohamed Nadour, Ahmed Essadki, Tamou Nasser,' Comparative analysis between PI \& Backstepping control strategies of DFIG driven by wind turbine

[18] Bossoufi, B., Karim, M., Lagrioui, A., Taoussi, M., Derouich, A.: Adaptive backstepping control of DFIG generators for variable-speed wind turbines system. J. Elect. Syst. 10, 317330 (2014)

[19] Hassan Salmi, Abdelmajid Badri, Mourad Zegrari, Aicha Sahel and Abdennaceur Baghdad, " Artificial Bee Colony MPPT control of Wind Generator without speed Sensors", International Conference on Electrical and Information Technologies (ICEIT 2017).

[20] Apalak, M.K., D. Karaboga, and B. Akay. 2014. The artificial bee colony algorithm in layer optimization for the maximum fundamental frequency of symmetrical laminated composit optimization for the maximum fundamental frequency of symmetrical laminated composite plates. Engineering Optimization 46(3):420-37

[21] Badre Bossoufi, Mohammed Karim, Ahmed Lagrioui, Mohammed Taoussi, Aziz Derouich Observer "backstepping control of DFIGGenerators for wind turbines variable-speed: FPGA-based implementation", Renewable Energy Volume 81, September 2015, Pages 903-917
[22] T.K Roy, M.A Mahmud; S.N. Islam; M. T. Oo Amanullah; "Direct Power Controller Design for Improving FRT Capabilities of DFIGBased Wind Farms using a Nonlinear Backstepping Approach", 2018 8th International Conference on Power and Energy Systems (ICPES)

[23] T.K Roy, M.A Mahmud; A.M.T. Oo , Nonlinear Backstepping Controller Design for Improving Fault Ride Through Capabilities of DFIG-Based Wind Farms. 2018 IEEE Power \& Energy Society General Meeting (PESGM)

[24] M El Ghamrasni, H Mahmoudi and B Bossoufi," Modelling and simulation of a wind system using variable wind regimes withBackstepping control of DFIG", 2018 IOP Conf. Ser.: Earth Environ. Sci. 161012026

[25] Adekanle O.S., Guisser M., Abdelmounim E., Aboulfatah M. (2019) Observer-Based Adaptive Backstepping Control of GridConnected Wind Turbine Under Deep Grid Voltage Dip. In: El Hani S., Essaaidi M. (eds) Recent Advances in Electrical and Information Technologies for Sustainable Development. Advances in Science, Technology \& Innovation (IEREK Interdisciplinary Series for Sustainable Development). Springer, Cham

[26] Chen Y. C. Pillay P. Khan A. 2005 PM Wind Generator Topologies IEEE Transactions on Industry Applications 416

[27] Slootweg, J.G., De Haan, S.W., Polinder, H., Kling, W.L.: Generalmodel for representing variable speed wind turbines in power system dynamics simulations. IEEE Trans. Power Syst. $18,144-151$ (2003)

Contribution of Individual Authors to the Creation of a Scientific Article (Ghostwriting Policy)

The authors equally contributed in the present research, at all stages from the formulation of the problem to the final findings and solution.

Sources of Funding for Research Presented in a Scientific Article or Scientific Article Itself

No funding was received for conducting this study.

\section{Conflict of Interest}

The authors have no conflicts of interest to declare that are relevant to the content of this article.

Creative Commons Attribution License 4.0 (Attribution 4.0 International, CC BY 4.0)

This article is published under the terms of the Creative Commons Attribution License 4.0 https://creativecommons.org/licenses/by/4.0/deed.en 